\title{
Structural Evolution of Metastable Protein Aggregates in the Presence of Trivalent Salt Studied by (V)SANS and SAXS
}

\author{
Andrea Sauter, ${ }^{\dagger}$ Fajun Zhang, ${ }^{*, \dagger}$ Noemi K. Szekely,${ }^{\ddagger}$ Vitaliy Pipich,,$\ddagger$ \\ Michael Sztucki, ${ }^{\sharp}$ and Frank Schreiber ${ }^{\dagger}$ \\ Institut für Angewandte Physik, Universität Tübingen, Auf der Morgenstelle 10, 72076 Tübingen, \\ Germany, Heinz Maier-Leibnitz Zentrum, Lichtenbergstr. 1, 85747 Garching, Germany, and \\ European Synchrotron Radiation Facility, 71 avenue des Martyrs, 38043 Grenoble Cedex 9, \\ France \\ E-mail: fajun.zhang@uni-tuebingen.de \\ Phone: +49 (0)7071 2978670. Fax: +49 (0)7071 295110
}

\section{Supporting Information}

SANS data fitting details: The SLD of the sample was fixed to $1.68 \cdot 10^{-6} \AA^{-2}$, the calculated value for BLG for neutrons of the used wavelength. The scattering contribution from protein clusters and dimers were described using a sum model. For the dimer contribution, a hard sphere structure factor was used with a spherical form factor (radius fixed to $15 \AA$ ). In case of the cluster, an ellipsoid form factor was used. Different structure factors were used for samples with different salt concentrations: a sticky hard sphere structure factor (perturbation parameter fixed to 0.01) was used for the sample with $12 \mathrm{mM} \mathrm{YCl}_{3}$, a hard sphere structure factor was used for the sample with $13 \mathrm{mM}$ salt and a screened Coulombic structure factor was used for the curves with 14 and $15 \mathrm{mM} \mathrm{YCl} 3$. Ionic strength, temperature and dielectric constant were fixed.

\footnotetext{
${ }^{*}$ To whom correspondence should be addressed

$\dagger$ Institut für Angewandte Physik, Universität Tübingen, Auf der Morgenstelle 10, 72076 Tübingen, Germany

†Heinz Maier-Leibnitz Zentrum, Lichtenbergstr. 1, 85747 Garching, Germany

${ }^{\text {II }}$ European Synchrotron Radiation Facility, 71 avenue des Martyrs, 38043 Grenoble Cedex 9, France
}

Table S1 Parameters for conventional fitting of involved structures at different length scales in samples with $67 \mathrm{mg} / \mathrm{ml} \mathrm{BLG}$ and $\mathrm{YCl}_{3}$ concentrations from 12 to $15 \mathrm{mM}$ (first measurement curve at $35^{\circ} \mathrm{C}$ and last measurement curve at $5^{\circ} \mathrm{C}$ ).

\begin{tabular}{lllll}
\hline & $\mathbf{1 2} \mathbf{~ m M}$ & $\mathbf{1 3} \mathbf{~ m M}$ & $\mathbf{1 4} \mathbf{~ m M}$ & $\mathbf{1 5} \mathbf{~ m M}$ \\
\hline $\begin{array}{l}\text { Dimer 35 } \\
\text { volume fraction }\end{array}$ & HS & HS & HS & HS \\
& & & & \\
Cluster 35 ${ }^{\circ} \mathbf{C}$ & SHS & HS & SC & SC \\
rotation axis $[\AA]$ & 35.8 & 32.9 & 32.6 & 30.1 \\
non-rotation axis $[\AA]$ & 93.4 & 86.4 & 89.4 & 90.9 \\
volume fraction & 0.054 & 0.038 & 0.069 & 0.095 \\
stickiness & 0.2 & - & - & - \\
charge & - & - & 0.12 & 4.95 \\
& & & & \\
Cluster 5 ${ }^{\circ} \mathbf{C}$ & $\mathrm{SHS}$ & $\mathrm{HS}$ & $\mathrm{SC}$ & $\mathrm{SC}$ \\
rotation axis $[\AA]$ & 50.1 & 44.1 & 44.8 & 42.6 \\
non-rotation axis $[\AA]$ & 97.4 & 98.5 & 105.6 & 106.9 \\
volume fraction & 0.025 & 0.101 & 0.132 & 0.175 \\
stickiness & 0.2 & - & - & - \\
charge & - & - & 0.18 & 4.94 \\
\hline
\end{tabular}



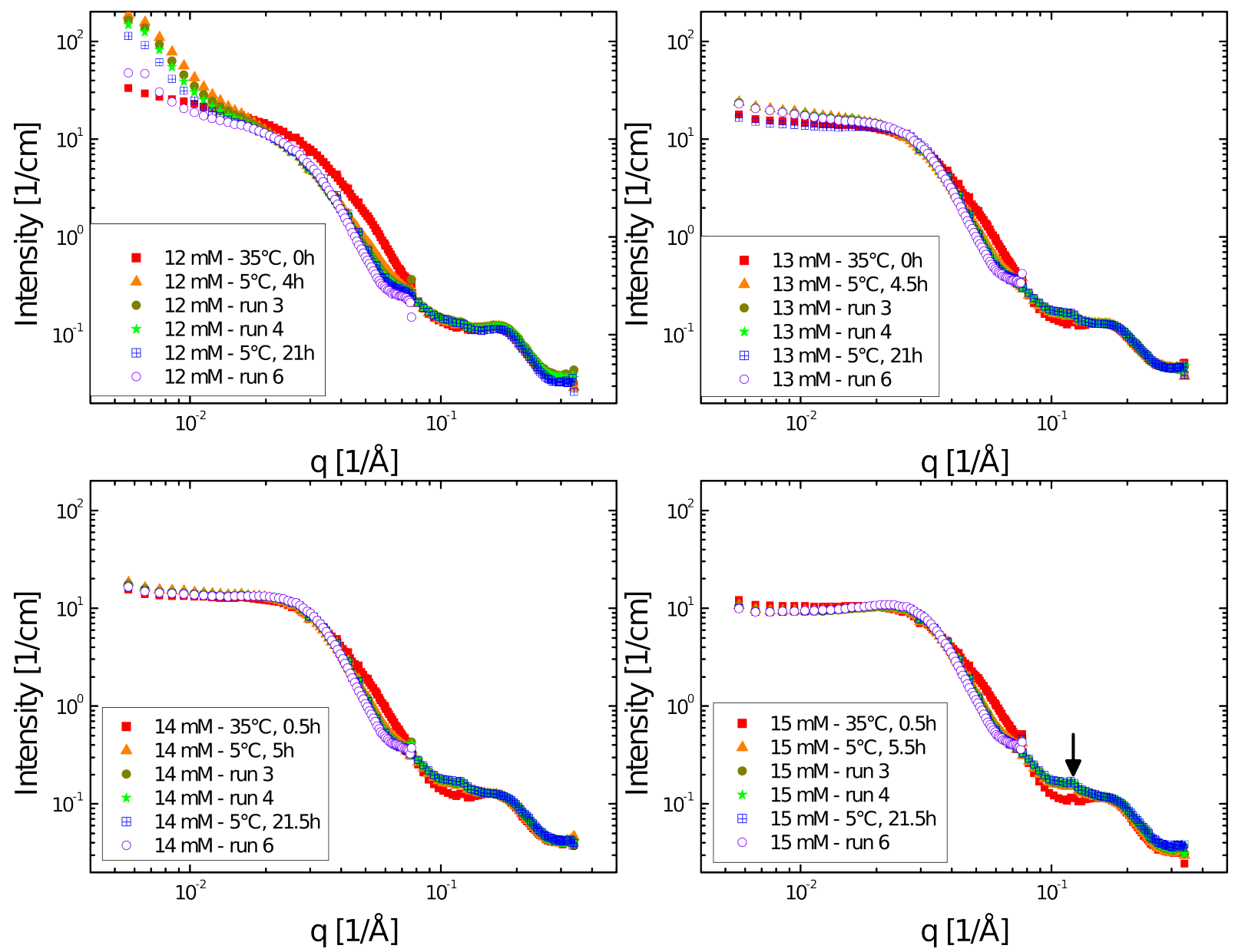

Figure S1 Complete set of SANS measurements for Figure 2 in the main text. 


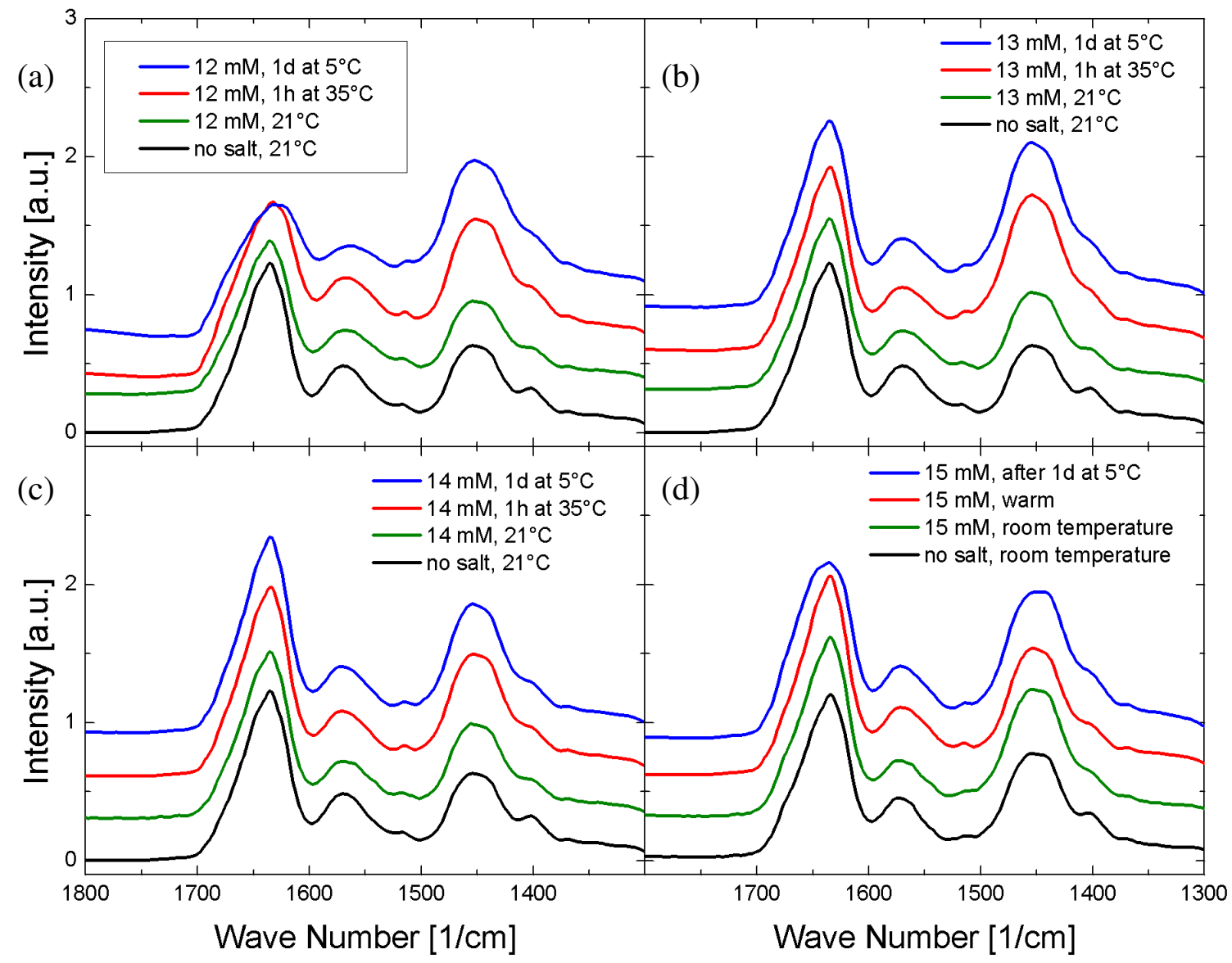

Figure S2 FTIR measurements of protein samples with a BLG concentration of $67 \mathrm{mg} / \mathrm{mL}$ without salt at room temperature (black) and with (a) $12 \mathrm{mM}$, (b) $13 \mathrm{mM}$, (c) $14 \mathrm{mM}$, and (d) $15 \mathrm{mM} \mathrm{YCl}_{3}$ at room temperature (green), after preparation and $1 \mathrm{~h}$ equilibration time at $35-38^{\circ} \mathrm{C}$ (red), and red marked sample after one day at $5^{\circ} \mathrm{C}$ (blue). Curves are shifted in intensity for better visibility. 